\title{
Physical activity and nutrition in older adults ${ }^{\dagger}$
}

\author{
AS Dontas ${ }^{1, *}$, J Moschandreas ${ }^{2}$ and A Kafatos ${ }^{2}$ \\ ${ }^{1}$ Hellenic Association of Gerontology-Geriatrics Kifissias 137, Athens 115-24, Greece \\ ${ }^{2}$ Department of Social Medicine, Preventive Medicine and Nutrition Clinic, P.O. Box 1393, University of Crete, \\ Heraklion, Crete, Greece
}

Accepted: 22 June 1999

\begin{abstract}
Physical activity and nutrient intake are important determinants of health throughout life. Many of the alterations in physiological structure and function that occur with age may result from disuse and disability as well as from diets deficient in energy, protein or other specific nutrients. Although a healthy diet can provide significant health benefits, diet alone, is not sufficient to provide optimal health, nor protect us from the hazards of sedentary habits. Nor is physical activity alone. The ideal combines sufficient exercise and a healthy diet.
\end{abstract}

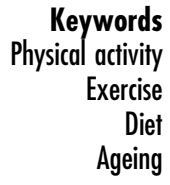

\section{Key messages}

- Interactions between physical activity and diet are important in old age, as activity can be poor because of disuse or musculoskeletal disability as well as inadequate energy intake. Diets are commonly deficient in persons in the community or institutions reporting disabilities.

- Rehabilitation measures with resistance exercise improve muscle strength and in association with nutritional supplements (17\% proteins) can lead to increased lean body mass and therefore restore physical independence in the elderly.

- Even in very old frail individuals combined exercise and dietary interventions are effective in enhancing muscle mass and spontaneous physical activity and may be associated with decreased overall mortality rate.

\section{Introduction}

During the second half of the 20th century an explosion in the numbers of the elderly has taken place throughout the world, particularly evident in economically developed countries and in subjects aged $>85$ years (the oldest old). These demographic changes, accompanied by life prolongations even at advanced ages and widely referred to as the 'longevity' revolution, are caused by the reduction of environmentally caused mortality at early ages and to a smaller degree to decreased mortality at late ages related to improvements in public health, nutrition and medical care. As a result, expectation of life at birth in 'developed' countries has almost doubled from a little over 40 years in 1900 to nearly 80 years today. The price paid for this achievement is that increasing numbers of people now survive to ages where disability, morbidity and mortality are high and the age structure of survivors very narrow. During this long period the lifestyle,particularly in the areas of physical activity and nutritional intake has special relationships with endogenous determinants of health which will be examined in this review.

This review will examine certain characteristics of persons of older ages especially those referred to as the 'oldest old'; the evolution of myoskeletal disability with advancing age and its relations with institutionalization and mortality; the modifying effects of moderate and mild physical activity on disability, use of services and survival; and the interrelations of physical activity and diet in old age.

\section{Characteristics of older persons}

From 1960 to 1990 the number of Americans $>65$ years of age increased by $88 \%$, that of persons $>85$ years of age by $225 \%$, whereas the total U.S. population increased by just $39 \%{ }^{1}$. More impressively, the 4 million Americans aged $>85$ years in 2000 are projected by the Census Bureau Middle Series to increase fourfold to almost 18 million by the year 2050, or to 31 million according to the Census Bureau Highest Series projections $^{2}$. Similar trends are expected to occur in many European countries, e.g. Greece (Table 1).

Distinction should thus be made between subjects aged from 65 to 85 years and those older than 85; the former usually have few health problems and few instances of disabilities of low intensity. In contrast, the latter are heterogeneous along health as well as economic lines; nearly half have serious health and 
Table 1 The elderly in Greece 1985-2020

\begin{tabular}{cccccc}
\hline & $\begin{array}{c}\text { Total } \\
\text { population }\end{array}$ & $\begin{array}{c}\text { Population } \\
>65 \text { years old }\end{array}$ & (\% Total) & $\begin{array}{c}\text { Population } \\
>85 \text { years old }\end{array}$ & $(\%$ Total) \\
\hline 1985 & $9,934,000$ & $1,328,000$ & 13.4 & 93,400 & 0.94 \\
1995 & $10,442,500$ & $1,596,000$ & 15.3 & 143,100 & 1.37 \\
2000 & $10,578,000$ & $1,783,000$ & 16.9 & 158,600 & 1.50 \\
2010 & $10,791,000$ & $2,045,000$ & 18.9 & 207,800 & 1.93 \\
2020 & $10,828,300$ & $2,260,000$ & 20.9 & 334,500 & 3.09 \\
\hline
\end{tabular}

Source $=$ National Statistical Service of Greece, 1996.

mobility problems; $60-70 \%$ have impaired hearing; vision and other sensory deficits are common, as are instability, falls, hip fractures and cardiovascular disease; finally, nearly a third of the very old have some degree of dementia ${ }^{3}$. The other half of this group, however, are healthy enough to live independently: $44 \%$ of men and $28 \%$ of women can be termed physically robust, i.e. able to perform at even higher levels of functioning than represented by ADLs and IADLs, such as walking one-quarter of a mile ${ }^{1}$, Inequalities and differences created previously in the lifecycles of these elite survivors (educational, lifestyle and labor market experiences) are carried into their very old age ${ }^{4}$. The very old subjects increase at a very fast rate (the fastest growing minority), and although the age-specific prevalence and the duration of lifetime disability appear to decline in newer cohorts, e.g. in France and the United States ${ }^{5}$, the absolute numbers of functionally impaired elderly will become larger as the population size of the oldest old expands rapidly ${ }^{6}$.

Body composition differs in the younger elderly compared to young adults and the older elderly ${ }^{7}$. Compared to subjects aged 20-25 years the younger elderly have a positive energy balance with an increase in body weight and centralized adiposity along with a moderate decrease in muscle and bone compartments of lean tissue ${ }^{8}$. The older elderly exhibit lower weight mostly because of large losses of lean body mass resulting from disuse and an inadequate intake of protein and energy resulting in a high prevalence of malnutrition. The large muscle and bone losses of the oldest old exert separate, adverse discrete actions on functional status and facilitate specific disease development in this heterogeneous group (muscle loss: lower resting metabolic rate, immune dysfunction, loss of muscle strength, slower gait velocity, functional disability; bone loss: osteoporotic fractures, chronic pain, mobility impairment, institutionalization). The importance of early screening and differentiation of muscle vs. bone loss in elderly subjects occurring even without weight change can not be overemphasized.

Some of these changes appear in Table 2 (reduced body weight and total serum cholesterol and increased fatness and systolic blood pressure) which contains data derived from 169 men aged 70-79 years, 55 men aged 80-84 years and 18 men aged 85-89 years, survivors of the 686 men of the original $40-59$ year old cohort of the Seven Countries Study ${ }^{9}$; the Table also indicates the significantly lower habitual activity in subjects $80-84$ and particularly $85-89$ years old.

Activity of growth hormone and testosterone, which promote lean tissue growth appears reduced in the very old; growth hormone therapy can in part correct such age-associated compositional changes and performance ${ }^{10}$. Similarly, resistance training during hypocaloric dieting augments lean mass while further reducing fat mass; resistance training may also offset the catabolic effects of low protein diets, which are widely used by elderly subjects with chronic renal failure $^{11}$.

In a classical introduction to 'Nutrition in the Elderly' (1992) HN Munro ${ }^{12}$ summarized as follows the dietary

Table 2 Anthropometric and biochemical measurements and physical activity in the Cretan men of the Seven Countries Study in 1991

\begin{tabular}{lccc}
\hline Measurements & $\begin{array}{c}\text { Age 70-79y } \\
(n=169)\end{array}$ & $\begin{array}{c}\text { Age 80-84y } \\
(n=58)\end{array}$ & $\begin{array}{c}\text { Age 85-89y } \\
(n=18)\end{array}$ \\
\hline Weight $(\mathrm{kg})$ & $70.3 \pm 13.3$ & $67.1 \pm 12.2$ & $66.5 \pm 14.5$ \\
Height $(\mathrm{cm})$ & $164.7 \pm 6.8$ & $163.9 \pm 6.4$ & $162.8 \pm 5.6$ \\
Systolic blood pressure $(\mathrm{mm} \mathrm{kg})$ & $156.8 \pm 20.9$ & $163.6 \pm 23.3$ & $195.5 \pm 34.5^{\star}$ \\
BMl $\left(\mathrm{kg} / \mathrm{m}^{2}\right)$ & $25.9 \pm 4.9$ & $24.9 \pm 3.8$ & $25.0 \pm 8.4$ \\
Triceps skinfold $(\mathrm{mm})$ & $11.5 \pm 5.5$ & $10.3 \pm 5.1$ & $12.2 \pm 8.4$ \\
Total serum cholesterol $(\mathrm{mg} / \mathrm{dl})$ & $224.2 \pm 40.4$ & $221.8 \pm 42.6$ & $190.7 \pm 42.1^{*}$ \\
Serum triglycerides $(\mathrm{mg} / \mathrm{dl})$ & $125.5 \pm 68.8$ & $120.8 \pm 69.9$ & $107.9 \pm 45.6$ \\
Physical activity (Kcal/wk) & $800.1 \pm 76.8$ & $440.2 \pm 65.4$ & $350.5 \pm 86.7^{*}$ \\
\hline
\end{tabular}

Means \pm SD. Data are derived from 245 survivors of the 1960 group.

Significantly different from $70-79$ y olds (ANOVA): ${ }^{*} p<0.05$ or less.

From Kafatos et al. 1997, modified. 
involvement in the aging process: 'First, changes in body composition and in organ function occur throughout adult life, making old age the recipient of adverse processes begun at earlier ages (e.g. loss of bone density leading to osteoporosis and fracture). Second, many degenerative diseases first assert themselves in middle life and persist into old age (e.g. cardiovascular diseases). Nutritional habits are prime factors in the etiology of some of these diseases. Third, the amounts of many individual dietary nutrients needed to maintain optimal health in old age still require quantification. This is important because the elderly tend to consume less food'. The present contribution discusses factors interrelating physical activity, diet and aging with respect to fitness and survival.

\section{Physical disability evolution; institutionalization and mortality}

Persons of advanced age with physical disabilities estimated by self- or proxy-reports, or preferably determined from standardized tests of physical performance usually have a low level of physical activity and require a variety of supportive measures to maintain their autonomy ${ }^{13-16}$. If progressive, these disabilities may lead to loss of independence and admission to long-term care facilities where physical activity is further sharply reduced, the reduction being accentuated by age-related comorbidity ${ }^{17-21}$. It has been estimated that $43 \%$ of Americans aged $>65$ years will enter a nursing home in their lives, and of these $25 \%$ of women and $13 \%$ of men will spend therein five years or more ${ }^{22}$. Even in healthy non-disabled persons simple performance-based scored measures of lower body function can identify persons who are at an increased risk of becoming disabled and in need of supportive measures ${ }^{18,23,24}$. Fears have been expressed, however, that cumulative lifetime disability could become longer if behavioural factors do not alter the onset or the progression of debilitating diseases of aging whereas effective treatment measures, whilst leading to further reductions of old age mortality, could also result in more years spent in chronic illness and disability ${ }^{25}$.

To test this 'expansion of morbidity' hypothesis an analysis from 1986 to 1994 of 1741 University of Pennsylvania alumni, classified on the basis of their midlife exercise patterns, body-mass index and smoking in three health risk groups, high, moderate and low, was carried out ${ }^{26}$. The onset of disability occurred more than five years later in the low-risk group than in the high-risk group. Furthermore, mortality rates were lower in the low-risk group (7.9\%) compared with the high-risk group (11.9\%) over the 8-year follow-up. This study indicates that better health-related behaviour can delay the onset and shorten duration of disability at the end of a life which has become only moderately longer, i.e. compress disability. Disability affecting lower extremities, i.e. resulting in walking difficulties, has been shown to increase markedly the risk of death of older subjects residing in the community ${ }^{27}$, or even in retirement homes ${ }^{28}$.

An appraisal of the physical status and ability to perform activities of daily living unaided was carried out in 1991 and 1997 on the survivors of the Cretan cohort of the Seven Countries Study, all community living when the ages of the surviving men were 71 to 90 years and 77 to 96 years respectively ${ }^{9}$. The disabilities in daily activities were estimated from self-reports of functional status to 16 questions adapted from the WHO-questionnaire (Table 3$)^{29}$. For each item the level of competence was measured on a 4-point scale. Grades of difficulty were assigned to categories defined in items of the ability to perform an activity (i.e. can do without difficulty/can do with difficulty but without help/can do only with help/unable to complete). From the items four combined activity/disability scores were calculated. The lower the score, the better the performance.

A total ability score (TAS) was calculated as the sum of all items. A mobility score (MS) was calculated as the sum of items 1, 3, 4 and 5 (move outdoors, use stairs, walk at least $400 \mathrm{~m}$, carry a heavy object). A self-care ability score (SCAS) was calculated as the sum of items 2, 6-10 and 14, reflecting the capacity to complete basic activities for bodily maintenance. ADL and IADL ability scores are those widely employed. If a person did not have difficulties in accomplishing any activity, their functioning was rated as good.

Table 4 indicates that all above disability scores (TAS, MS, SCAS, ADL, IADL) differentiated the 6-year survivors from those deceased in 1991-1997, men not alive in 1997 having worse ability in 1991, indicated by the higher scores ${ }^{30}$.

Table 3 Items used for assessing activities of daily living

1. Move outdoors
2. Walk between rooms
3. Use stairs
4. Walk at least $400 \mathrm{~m}$
5. Carry a heavy object, e.g. a shopping bag of $5 \mathrm{~kg}$ for $100 \mathrm{~m}$
6. Use the toilet
7. Wash yourself
8. Dress and undress
9. Get in and out of bed
10. Cut toe-nails
11. Use the telephone
12. Take own medication
13. Manage finances
14. Feed yourself
15. Do light housework (wash dishes, sweep floors)
16. Do heavy housework (wash windows and floors, general house
cleaning)


Table 4 Average 1991 ability scores with 95\% C.L.s in 254 survivors of the 1960 Crete cohort and 1991 ability scores by vital status in 1997

\begin{tabular}{|c|c|c|c|c|c|c|c|}
\hline \multirow[b]{2}{*}{ Score } & \multicolumn{2}{|c|}{ All subjects $(n=254)$} & \multicolumn{2}{|c|}{ Alive in $1997(n=161)$} & \multicolumn{2}{|c|}{ Not alive in $1997(n=93)$} & \multirow{2}{*}{$\begin{array}{c}\text { ANCOVA+ } \\
p \text {-value }\end{array}$} \\
\hline & Mean (sd) & $95 \% \mathrm{Cl}$ & Mean (sd) & $95 \% \mathrm{Cl}$ & Mean (sd) & $95 \% \mathrm{Cl}$ & \\
\hline TAS & $24.7(10.95)$ & $(23.7,26.0)$ & $21.5(8.51)$ & $(20.1,22.8)$ & $30.2(12.43)$ & $(27.6,32.8)$ & $<0.0001$ \\
\hline MS & $7.0(3.71)$ & $(6.6,7.5)$ & $5.9(3.12)$ & $(5.4,6.4)$ & $8.9(3.91)$ & $(8.1,9.7)$ & $<0.0001$ \\
\hline SCAS & $10.1(4.27)$ & $(9.6,10.6)$ & $9.0(3.27)$ & $(8.4,9.5)$ & $12.1(5.03)$ & $(11.0,13.1)$ & 0.0025 \\
\hline Basic ADL & $10.0(4.26)$ & $(9.5,10,6)$ & $8.9(3.25)$ & $(8.4,9.4)$ & $12.0(5.00)$ & $(11.0,13.1)$ & 0.0021 \\
\hline IADL & $14.6(6.95)$ & $(13.8,15.5)$ & $12.6(5.56)$ & $(11.7,13.5)$ & $18.2(7.69)$ & $(16.6,19.8)$ & 0.0002 \\
\hline
\end{tabular}

TAS (Total Ability Score) Sum (Q1-Q16).

MS (Mobility Score) Q1 + Q3 + Q4 + Q5.

SCAS (Self-Care Ability Score) Q2+Q6+Q7+Q8+Q9+Q10+Q14.

Basic ADL (Activities of Daily Living) Q2 + Q3 + Q6 + Q7 + Q8+Q9+Q14.

IADL (Instrumental ADL) Q1+Q4+Q5+Q10+Q11+Q12+Q13+Q15+Q16.

ANCOVA + adjusted for age at entry.

In addition to physical disabilities, objective markers of clinical disease in hospitalized community-living subjects aged $>65$ years, male gender, and various indicators of frailty (e.g. hypoalbuminemia), have been shown to be better predictors of 5-year mortality than was the clinical history of disease ${ }^{31}$.

Further, three functional measures studied in hospital patients $>70$ years old and representing broader domains of functional competence -physical (any impairment in IADLs), cognitive $(\mathrm{MMSE}<20)$ and psychological (GDS > 7)-have also been recently identified as accurate predictors of 3-months and 2-years mortality ${ }^{32}$. These data highlight the positive association between presence of physical, cognitive or psychological impairments, risk of institutionalization and early death in community dwelling or hospitalized subjects.

\section{Physical activity and modification of disability and survival}

The modifying effect of regular physical activity on the development of disability is an important public health issue because of the many adverse outcomes of long-term inactivity due to disability. It is, however, a difficult problem of post hoc ergo propter hoc demonstration; cross-sectional comparisons of disability differences between groups of physically active and groups of sedentary subjects may be inconclusive if the active subjects are self-selected because of better health at baseline rather than becoming healthier as a result of habitual physical activity. Longitudinal studies may also be inconclusive if vigorous physical activity leads to development of osteoarthritic changes and disability from injuries so that the trend lines of disability development in the active and those in the sedentary group may eventually converge.

Various long-term follow-up studies have shown that cardiovascular mortality rates are lower in men with moderately vigorous sports activity ${ }^{33,34}$, as well as high levels of physical fitness, an easily quantifiable measure of exercise capacity ${ }^{35}$. The effects of physical activity on the time course of disability and morbidity, however, are not as clearcut. Two recent studies, an 8-year prospective longitudinal study of habitually vigorously running persons aged 50 to 72 years ${ }^{36}$, and a 18-month study of an aerobic and a resistance exercise group in persons 50 to 65 years old with symptomatic knee osteoarthritis ${ }^{37}$ have both shown slower development of disability and modest but consistent improvement in knee pain and performance measures compared with controls participating in health education programs. The first study (Fries et $a l^{36}$ ) also showed significantly lower mortality in the runners' club members. The above interventions were long-term, high intensity activities resulting in a number of drop-outs in subjects taking part in the exercise groups. A study of quality of life and disability measures in 194 previously sedentary persons 50 to 65 years old participating in endurance exercises showed substantial improvement at 12 months in both measures and a dose-response relation with the amount of exercise ${ }^{38}$.

\section{Physical activity of lesser intensity; modification of use of services}

Regular physical activity reduces the risk for several major chronic diseases and conditions, as varied as coronary heart disease and colon cancer ${ }^{39}$. Exercise, as a subset of physical activity, is planned, structured, and repetitive bodily movement done to improve one or more components of physical fitness. Two recent studies have indicated that lesser quantities and intensities of physical activity, e.g. 30 minutes of moderate-intensity physical activity on most days of the week by middle-aged men and women, aged $<60$ years, have similar effects on weight, cardiorespiratory fitness, body composition and blood pressure as do traditional structured exercise programs ${ }^{40,41}$.

The effects of walking, an activity of still lower intensity, in influencing long-term mortality have also been reported in three recent studies: in the first, 707 non-smoking men, 61 to 81 years of age, enrolled in the Honolulu Heart Program were followed over 12 years ${ }^{42}$. The mortality rate among the men who 
walked less than 1 mile per day was nearly twice that among those who walked more than 2 miles per day ( $40.4 \%$ vs. $23.8 \%, \mathrm{P}=0.001$ ), after adjustment for age and other possible risk factors. In the second, 802 Dutch men, aged 64 to 87 years were followed for 10 years and classed according to time spent on physical activity (walking or cycling 3 times per week). No simple type of activity was particularly protective, but walking or cycling was associated with reduced mortality from coronary heart disease and all cause death (relative risk of highest tertile to lowest tertile of total physical activity $0.71 ; 95 \%$ C.I. $0.50-0.88)^{43}$. In the third study moderate levels of occupational and leisure-time physical activity appeared to exert a protective effect on all-cause mortality in Goteborg women $^{44}$. These reports are important in view of the modest amounts of effort required in simple activities, such as walking compared to more vigorous exercise.

In the Nottingham Longitudinal Study of Activity and Ageing ${ }^{45}$, low levels of customary physical activity of community living persons aged $>65$ years were associated with a higher mortality and an increased likelihood of using health and personal social services 8 years after the initial interview compared with subjects reporting moderate or high non-structured activity ${ }^{46}$.

Ever since 1972 WHO has stressed that good health is as fundamental as long life as an objective of human activity and that efforts should be made to reduce the emergence of chronic disease and disability in populations with long survival and declining death rates at high ages. The identification and measurement of healthy life expectancy is presently an actively pursued target in world public health and is the central theme of WHO activities during the international year of the Elderly in 1999.

\section{Interaction of physical activity and diet}

Diet is one of the key factors influencing health and physical activity at all ages as evidenced by many contributions in the present workshop. Epidemiologic studies commonly have demonstrated nutritional deficits in $10-20 \%$ of elderly people living at home and up to $60 \%$ in persons living in institutions in parallel with chronic disease, loss of weight and physical dependence ${ }^{47}$. In recently institutionalized subjects, habitual physical activity is inevitably reduced to very low levels as a result of the non-necessity of carrying out small errands and household duties within an all-providing environment. Even active, non-disabled individuals on entry tend to adapt to the inactive lifestyle which most residential homes reserve for their senior citizens.

We possess relatively few data relating functional status, physical activity and diet in community living older people followed for long periods. In the remaining section of this presentation reference will be made to the relationship between the presence of physical disabilities and dietary intake among the 30-year survivors of the Seven Countries Study original cohorts, specifically elderly men from Finland, The Netherlands and Italy. These men initially examined at the age of 40-60 years in five European countries, Japan and the U.S. were fit at entry, with habitual physical activity ranging from sedentary (desk workers) to extremely heavy (lumberjacks).

The clinical examinations and questionnaires were collected according to the international protocol used in all surveys of the Seven Countries Study. The food intake data were collected by the cross-check dietary history method adapted to the local situation; each participant was interviewed together with the person who prepared the food about his usual food consumption on weekdays and during weekends. Self-reported functional status and physical activity were estimated from responses to the WHOquestionnaire and a questionnaire designed for retired men by Professor JN Morris (London School of Physical and Tropical Medicine), respectively. Men were classified as 'disabled' if they reported needing help with at least one of the mobility or basic ADL items.

Dietary information gathered in 1990 from 1152 men aged 70-90 years in Finland, The Netherlands and Italy (the FINE study, a follow-up of the survivors of the Seven Countries Study reported by Huijbregts) ${ }^{48}$, indicates that total energy intake was inversely associated with the subjects' functional status after adjustment for age (Table 5).

Among the 236 men reporting disabilities energy intake was $13 \%$ lower than among those non-disabled. Mean body mass index in $\mathrm{kg} / \mathrm{m}^{2}$ did not differ significantly between normal and disabled men (Finland 26.7 and 25.8, The Netherlands 25.6 and 25.2, Italy 26.1 and 25.9). However, a significant difference in physical activity between the disabled and non-disabled men was present in all three countries and the lower energy intake of subjects with disabilities could largely but not completely be explained by their lower physical activity. This ranged between 4.0 and 5.6 hours/week compared with 10.3 and 15.1 hours/week in the non-disabled elderly. Subjects with disabilities made up $18 \%$ of the men in The Netherlands, $21 \%$ in Finland and $24 \%$ in Italy. Although the levels of energy intake were moderately lower in the disabled men the possibility remains that more disabled non-participants in the study had still more inadequate energy and nutrient intake. This brings into focus the propensity of development of deficiency states and sarcopenia in physically underactive and undernourished elderly (Table 6).

A similar study on more than 1000 non-institutionalized men and women aged $70-75$ years from an urban 
Table 5 Mean daily intake of selected nutrients by country by functional status of men participating in the FINE-study (1989-1991)

\begin{tabular}{|c|c|c|c|c|c|c|}
\hline & \multicolumn{2}{|c|}{ Finland } & \multicolumn{2}{|c|}{ The Netherlands } & \multicolumn{2}{|c|}{ Italy } \\
\hline & Able bodied & Disabled & Able bodied & Disabled & Able bodied & Disabled \\
\hline Number & 179 & 47 & 426 & 92 & 311 & 97 \\
\hline Energy (MJ) & 11.8 & $10.4^{*}$ & 8.9 & $8.3^{*}$ & 10.3 & $9.2^{*}$ \\
\hline Energy excl. alcohol (MJ) & 11.7 & $10.3^{\star}$ & 8.7 & $8.1^{*}$ & 9.1 & $8.1^{*}$ \\
\hline Protein $(\mathrm{g})$ & 103 & $90^{*}$ & 76 & 72 & 79 & $69^{*}$ \\
\hline Fat $(\mathrm{g})$ & 118 & $101^{*}$ & 91 & 86 & 79 & $66^{*}$ \\
\hline Carbohydrates (g) & 325 & $294^{*}$ & 234 & $215^{*}$ & 284 & $262^{*}$ \\
\hline Protein (En\%) & 14.8 & 14.8 & 14.6 & 14.8 & 13.0 & 12.9 \\
\hline Fat $(\mathrm{En} \%)$ & 37.6 & 36.4 & 38.0 & 38.9 & 29.2 & $27.4^{*}$ \\
\hline Carbohydrates (En\%) & 46.4 & 47.9 & 44.1 & 43.7 & 46.6 & $48.8^{*}$ \\
\hline
\end{tabular}

*Significantly different from normal group $(P<0.05)$; En\%=percentage of energy intake.

Table 6 Disability, Inactivity, Undernutrition in old age

\begin{tabular}{lll}
\hline Physical disabilities & May lead to & Low levels of physical activity \\
Reduced physical activity & May lead to & Physical dependence \\
Physical dependence & May lead to & Supportive-rehabilitative measures \\
& May lead to & Admission to long-term care facilities \\
Life In long-term care facilities & May lead to & Physical inactivity \\
Physical inactivity & May lead to & Anorexia, undernutrition \\
Undernutrition & May lead to & Sarcopenia, weakness \\
\hline
\end{tabular}

area in northern Italy investigated the association of functional status with nutritional intake ${ }^{49}$. A higher prevalence of persons who consumed less than two thirds of the recommended daily allowance for protein, vitamins A, B12, C, niacin and iron was observed among those reporting one or more functions lost compared to those reporting no functions lost. These two studies indicate that elderly subjects reporting disabilities have lower intakes of important dietary items than subjects reporting no disabilities.

The demonstration of increase in muscle strength, muscle area, creatinine excretion, and decrease in body fat in healthy men in their $60 \mathrm{~s}$ and $70 \mathrm{~s}^{50,51}$, and in much older sarcopenic nursing home residents of both sexes with mean age 87 years by resistance exercise programmes without nutritional supplementation but particularly with it $(360$ or $560 \mathrm{kcal} /$ day, $17 \%$ protein $)^{52,53}$, indicates the reversibility of such conditions even in the oldest old. Additional clinical benefits of exercise training obtained by these very old persons included higher overall levels of spontaneous physical activity and gait velocity.

Disabilities accompanying dementia (choosing, chewing, swallowing food) can lead to inadequate food intakes and thus to weight loss in dependent nursing home elderly ${ }^{54}$; the impact of this erupting disease in advanced old age on physical dysfunction and inadequate intake of multiple items represents a new threat for a large percentage of the very old.

Finally, visual and somatosensory inputs appear to be necessary for older adults to retain control of balance and functional status within suboptimal or changing environmental contexts ${ }^{55}$; cataract surgery appears to be an effective means of improving functional capacity in patients in their 70 s with positive results on visual acuity, ADL scores, and mental status measures ${ }^{56}$.

Physical activity and chronic illness determine, in addition to total energy intake, the protein requirements in old age. Subjects with low habitual physical ability but no debilitating disease can be maintained on an average daily intake of 0.8 to $1.0 \mathrm{~g}$ protein per $\mathrm{kg}$ of body weight; individuals with chronic wasting diseases require additional amounts of protein, e.g. $0.2 \mathrm{~g} / \mathrm{kg}$, to remain in balance ${ }^{57}$.

On the other hand the adverse effects of high protein intakes on the failing kidney have to be weighed. Numerous studies have demonstrated the acceleration of renal failure by high protein intakes as well as the slowing of deterioration of renal function by low protein diets ${ }^{58}$. The negative effect of a high dietary protein on the failing kidney vs. its positive action in hypoproteinaemic states requires careful consideration for practical diet programming. Studies in progress are expected to determine whether the catabolic effects of a low-protein diet can be offset by long-term resistance training.

\section{Conclusions}

Interactions between levels of physical activity, muscle function and diet remain positive in late life. Physical impairments and chronic illness negatively affect total energy and specific nutrients' intake; even in very old, frail subjects, however, active resistance training and adequate energy intake may improve muscle strength and body balance and reverse trends commonly described as irreversible. Recent evidence suggests 
further that even low-intensity, regular activity in physically able older men and women is associated with a reduced overall mortality rate.

\section{References}

1 Suzman RM, Willis DP, Manton KG. The oldest old. New York: Oxford Univ. Press, 1992.

2 Day JC. Population projections of the United States by age, sex, race and hispanic origin: 1995 to 2050 (Current Population Reports, Bureau of the Census, U.S. Printing Office, Washington DC) 1996.

3 Skoog I, Nilsson L, Palmertz B, Andreasson A, Svanborg A. A population-based study of dementia in 85 year-olds. $N$. Engl. J. Med. 1993; 328: 153-8.

4 Campion EW. The oldest old. N. Engl. J. Med. 1994; 330 1819-20.

5 Robine JM, Mormiche P, Sermet C. Examination of the causes and mechanisms in the increase in disability-free life expectancy. J. Aging Health 1998; 10: 171-91.

6 Olshansky SJ, Wilkins R. Introduction. J. Aging Health 1998; 10 (Special Issue): 123-35.

7 Steen B. Body composition and aging. Nutr. Rev. 1988; 46: $45-51$.

8 Glick Z. Energy balance in the elderly. In: Munro H, Schlierf G, eds. Nutrition of the Elderly. Nestle Nutrition Services, New York. Raven Press 1992: 99-106.

9 Kafatos A, Diacatou A, Voukiklaris G, Nikolakakis N, Vlachonikolis J, Kounali D, Mamalakis G, Dontas AS. Heart disease risk-factor status and dietary changes in the Cretan population over the past $30 \mathrm{y}$ : the Seven Countries Study. Am. J. Clin. Nutr. 1997; 65: 1882-6.

10 Rudman D, Feller AG, Nagraj HS, Gergans GA, Lalitha PY, Goldberg AF, Schlenker RA, Cohn L, Rudman IW, Mattson DE. Effects of human growth hormone in men over 60 years old. N. Engl. J. Med. 1990; 323: 1-6.

11 Fiatarone Singh MA. Combined exercise and dietary intervention to optimize body composition in aging. Ann. NY Acad. Sci. 1998; 854: 378-93.

12 Munro H, Schlierf G. Nutrition of the Elderly Nestle Nutrition Workshop Series. Vol 29, Raven Press, N.Y. 1992.

13 Hadley EC, Ory M, Suzman R, et al. Physical frailty: A treatable cause of dependence in old age. J. Gerontol. 1993; $\mathbf{4 8}$ (Special Issue): 3-88.

14 Manton KG. Past and future life expectancy increases at later ages; their implications for the linkage of chronic morbidity, disability, and mortality. J. Gerontol. 1986; 41: 672-81.

15 Rogers A, Rogers RG, Belanger A. Longer life but worse health? Measurement and dynamics. Gerontologist 1990; 30: 640-9.

16 Zarit SH, Johansson B, Malmberg B. Changes in functional competency in the oldest old. J. Aging Health 1995; 7: 3-23.

17 Guralnik JM, Simonsick EM. Physical disability in older Americans. J. Gerontol. 1993; 48 (Special Issue): 3-10.

18 Guralnik JM, Ferrucci L, Simonsick EM, Salive ME, Wallace RB. Lower-extremity function in persons over the age of 70 years as a predictor of subsequent disability. N. Engl.J. Med. 1995; 332: 556-61.

19 Reuben DB, Siu AL, Kimpau S. The predictive validity of selfreport and performance-based measures of function and health. J. Gerontol. 1992; 47: M106-10.

20 Williams ME, Gaylord SA, Gerrity MS. The timed manual performance test as a predictor of hospitalization and death in a community-based elderly population. J. Am. Geriatr. Soc. 1994; 42: 21-7.

21 Zarit SH, Johansson B, Berg S. Functional impairment and co-disability in the oldest old. J. Aging Health 1993; 5: 291-305.

22 Kemper P, Murtaugh CM. Lifetime use of nursing home care. N. Engl.J. Med. 1991; 324: 595-600.
23 Fried LP, Herdeman SJ, Kuhn KE, et al. Preclinical disability : hypothesis about the bottom of the iceberg. J. Aging Health 1991; 3: 285-300.

24 Ostir GV, Markides KS, Black SA, Goodwin JS. Lower body functioning as a predictor of subsequent disability among older Mexican American. J. Gerontol. Med. Sci. 1998; 53A: M491-5.

25 Olshansky SJ, Carnes BA, Cassel CK. The aging of the human species. Scientific American 1993; 268: 46-52.

26 Vita AJ, Terry RB, Hubert HB, Fries JF. Aging, health risks and cumulative disability. N. Engl. J. Med. 1998; 338: 103541.

27 Bennett D, Beckett L, Murray A, et al. Prevalence of parkinsonian signs and associated mortality in a community population of older people. N. Engl.J. Med. 1996; 334: 71-6.

28 Dontas AS, Toupadaki H, Tzonou A, Kasviki-Charvati P. Survival in the oldest old; death risk factors in old and very old subjects. J. Aging Health 1996; 8: 220-37.

29 Heikkinen E, Waters WE, Brzezinski ZJ (eds). The elderly in eleven countries. A sociomedical survey. Copenhagen: World Health Organization, Regional Office for Europe, 1983.

30 Moschandreas I, Kafatos A, (personal communication).

31 Fried LP, Kronmal RA, Newman AB, et al. Risk factors for 5-year mortality in older adults. JAMA 1998; 279: 585-92.

32 Inouye SK, Reduzzi PN, Robison JT, Hughes JS, Horwitz RL, Concato J. Importance of functional measures in predicting mortality among older hospitalized patients. JAMA 1998; 279: 1187-93.

33 Paffenbarger RS, Hyde RT, Wing AL, Lee IM, Jung DL, Kampert JB. The association of changes in physical-activity level and other lifestyle characteristics with mortality among men. N. Engl. J. Med. 1993; 328: 538-45.

34 Curfman GD. The health benefits of exercise. N. Engl. J. Med. 1993; 328: 574-6.

35 Sandvik L, Erikssen J, Thaulow E, Erikssen G, Mundal R, Rodahl K. Physical fitness as a predictor of mortality among healthy, middle-aged Norwegian men. N. Engl.J. Med. 1993; 328: $533-7$.

36 Fries JF, Singh G, Morfeld D, Hubert HB, Lane N, Brown Jr, BW. Running and the development of disability with age. Ann. Int. Med. 1994; 121: 502-9.

37 Ettinger WH, Burns R, Messier SP, Applegate W, Rejeski WJ, Morgan T, Shumaker S, Berry MJ, O’Toole M, Monu J, Crave $\mathrm{S}$. A randomized trial comparing aerobic exercise and resistance exercise with a health education program in older adults with knee osteoarthritis. The Fitness Arthritis and Seniors Trial (FAST). JAMA 1997; 277: 25-31.

38 Stewart AL, King AC, Haskell WL. Endurance exercise and health related quality of life in $50-65$ years old adults. Gerontologist 1993; 33: 782-9.

39 U.S. Department of Health and Human Services. Physical Activity and Health. A report of the Surgeon General. C.D.C. Press. Nat. Center for Chronic Disease and Health Promotion 1996.

40 Dunn AL, Marcus BH, Kampert JB, Garcia ME, Kohl HW, Blair SN. Comparison of lifestyle and structured interventions to increase physical activity and cardiorespiratory fitness: a randomized trial. JAMA 1999; 281: 327-34.

41 Andersen RE, Wadden TA, Bartlett SJ, Zemel B, Verde TJ, Franckowiak SC. Effects of lifestyle activity vs structured aerobic exercise in obese women: a randomized trial. JAMA 1999; 281: 335-40.

42 Hakim AA, Petrovitch H, Burchfiel CM, Ross GW, Rodriguez BL, White LR, Yano K, Curb JD, Abbott RD. Effects of walking on mortality among nonsmoking retired men. $N$. Engl. J. Med. 1998; 338: 94-9.

43 Bijnen FC, Caspersen CJ, Feskens EJ, Saris WH, Mosterd WL. Physical activity and 10-year mortality from cardiovascular diseases and all causes: The Zutphen elderly study. Arch. Intern. Med. 1998; 158: 1499-505. 
44 Lissner L, Bengtsson C, Bjorkelund C, Wedel H. Physical activity levels and changes in relation to longevity. Am. J. Epid. 1996; 143: 54-62.

45 Morgan K. Introduction. Age Ageing 1998; 27: 3.

46 Bath PA, Morgan K. Customary physical activity and physical health outcomes in later life. Age Ageing 1998; 27-S3: 29-34.

47 Clarke DM, Wahlqvist ML, Strauss BJG. Undereating and undernutrition in old age: integrating bio-psychosocial aspects. Age Ageing 1998; 27: 527-34.

48 Huijbregts PPCW. Dietary patterns and health in the elderly; a north-south comparison in Europe. Thesis, Wageningen, 1997.

49 Bianchetti A, Rozzini R, Carabelese C, et al. Nutritional intake, socioeconomic conditions, and health status in a large elderly population. J. Am. Geriatr. Soc. 1990; 38: 521-6.

50 Frontera WR, Meredith CN, O'Reilly KP, Knutgen HG, Evans WJ. Strength conditioning in older men: skeletal muscle hypertrophy and improved function. J. Appl. Physiol. 1988; 64: 1038-44.

51 Meredith CN, Frontera WR, O'Reilly KP, et al. Body composition in elderly men: Effect of dietary modification during strength training. J. Am. Geriatr. Soc. 1992; 40: 155-62.
52 Fiatarone MA, Marks EC, Ryan ND, et al. High-intensity strength training in nonagenarians: effects on skeletal muscle. JAMA 1990; 263: 3029-34.

53 Fiatarone MA, Evans WJ. The etiology and reversibility of muscle dysfunction in the aged. J. Gerontol. 1993; 48 (Special Issue): 77-83.

54 Berkhout AMM, Cools HJM, van Houwelingen HC. The relationship between difficulties in feeding oneself and loss of weight in nursing-home patients with dementia. Age Ageing 1998; 27: 637-41.

55 Woollacott MH. Age-related changes in posture and movement. J. Gerontol. 1993; 48 (Special Issue): 56-60.

56 Applegate WB, Miller ST, Graney MJ, et al. Impact of cataract surgery with lens implantation on vision and physical function in elderly patients. JAMA 1987; 257: 1064-6.

57 Kritchevsky D. Protein requirements of the elderly. In: Munro H. Schlierf G, eds. Nutrition of the Elderly. Nestle Nutrition Services, New York. Raven Press 1992; 109-17.

58 Klahr S, Levey AS, Beck GJ, Caggiula AW, Hunsicker L, Kusek JW, Striker G. The effects of dietary protein restriction and blood-pressure control on the progression of chronic renal disease. N. Engl. J. Med. 1994; 330: 877-83. 